\title{
Morphology of the endothelium over atherosclerotic plaques in human coronary arteries
}

\author{
MICHAEL J DAVIES, * NEVILLE WOOLF, $\dagger$ PETER M ROWLES, $\dagger$ JOHN PEPPER \\ From the $\star$ British Heart Foundation Cardiovascular Pathology Unit, St George's Hospital Medical School; \\ + Bland-Sutton Institute of Pathology, Department of Histopathology, University College and Middlesex \\ School of Medicine; and $\ddagger$ South West Thames Regional Cardiothoracic Unit, St George’s Hospital, London
}

SUMMARY The right coronary arteries of six hearts removed from patients with atherosclerosis, who were undergoing cardiac transplantation, were perfused with $2 \%$ buffered glutaraldehyde for 20 minutes before preparation for scanning electron microscopy. Perfusion was started within five minutes of explantation. In two patients the artery was angiographically normal, in one it was irregular in outline, and three had focal segments with significant stenosis. None of the patients had concentrations of plasma lipids above, $5.5 \mathrm{mmol} / 1$. The endothelial surface showed widespread focal abnormalities ranging from adhesion and migration of monocytes to loss of individual endothelial cells. Larger areas of endothelial denudation with exposure of underlying collagen were also seen consistently. Loss of endothelial cells was associated with accumulation of monocytes, on and deep to the surface, as well as adhesion of platelets to the exposed subendothelial tissue.

These results accord with the endothelial damage and platelet adhesion seen in hyperlipidaemic animals fed a high lipid diet.

Lesions resembling those seen in human atherosclerosis were induced by diets rich in fat that caused hyperlipidaemia in a wide range of animals including pigs, ${ }^{1}$ rodents, ${ }^{2}$ rabbits, ${ }^{3}$ and primates. $^{46}$ Hyperlipidaemia caused by inherites abnormalities of lipid metabolism in the rabbit also led to the development of atherosclerosis. ${ }^{78}$ These animal models permitted the sequence of changes in the vessel wall to be followed serially, and they consistently showed that the first morphological change in the development of atherosclerosis was adhesion of monocytes to an intact endothelial surface followed by their migration into the intima, ${ }^{2}$ a process that begins within 12 days of the start of a high lipid diet in primates." By 1'? weeks sufficient foam cells appeared within the intima to form fatty streaks and most of these lipid filled cells were believed to be macrophages. ${ }^{3910}$

Demonstrable morphological changes were preceded by an increased rate of replication of endothelial cells ${ }^{11}$ associated with enhanced per-

Requests for reprints to Professor Michael J Davies, British Heart Foundation Cardiovascular Pathology Unit, St George's Hospital Medical School, Cranmer Terrace, London SW17 ORE.

Accepted for publication 23 August 1988 meability to Evans Blue and it was at such sites that monocyte adhesion occurred. ${ }^{12}$ It has been suggested that the early increase in the turnover of endothelial cells is associated with increased desquamation of endothelial cells ${ }^{13}$ but not with exposure of the subendothelial collagen. The mechanism by which monocytes react with intact endothelial cells is unclear. On one hand, hyperlipidaemia may produce functional changes in the endothelial and smooth muscle cells-for example, increasing the expression of factors that are chemotactic for monocytes. ${ }^{14}$ On the other hand, hyperlipidaema or hyperfibrinogenaemia may enhance the capacity of circulating monocytes to adhere to endothelial surfaces. ${ }^{15-17}$

The appearance of fibro-lipid plaques in animal models of atherosclerosis was associated with a considerable increase in the adhesion of monocytes to the endothelial surface and morphological evidence suggesting that lipid filled macrophages were both entering and leaving the intima. ${ }^{518}$ At this stage, usually 3-4 months after the onset of hyperlipidaemia, smooth muscle migration into the intima was also well established. The presence of large aggregates of lipid filled macrophages then became associated with focal defects in the endothelial lining that exposed collagen, and in some models platelet adhesion was seen in such areas. ${ }^{519}$ 
Animal models have therefore given considerable insights into the injury of the arterial wall caused by hyperlipidaemia. All animal models, however, have limitations ${ }^{20}$ and we cannot be certain that the sequence of cellular change is the same in humans who are not clinically hyperlipidaemic but who have atherosclerosis.

It is difficult to obtain suitable material in which to examine the endothelium over human atherosclerotic plaques. After death deposition of a superficial layer of polymerised fibrin on the inner surface of the vessel makes it impossible to see the underlying endothelium clearly by scanning electron microscopy. Endarterectomy specimens are a source of atherosclerotic plaques from living patients but damage during sugical removal leads to considerable artefactual change in the endothelium. Many of the difficulties in assessing the integrity of the endothelium over atherosclerotic lesions in human beings can be overcome by examination of explanted hearts removed during cardiac transplantation. We report the results of a preliminary study of six such hearts.

\section{Patients and methods}

Hearts were obtained from six patients undergoing cardiac transplantation. All six had varying degrees of coronary atherosclerosis. Five were male and one was female, and all were less than sixty. Plasma total cholesterol concentrations ranged from 2.0 to 5.5 $\mathrm{mmol} / \mathrm{l}$; plasma triglyceride concentrations were not raised. In two of the patients the right coronary artery was angiographically normal; in one it had an irregular outline, and in three there were segments showing severe stenosis. In all cases the hearts were removed at operation after cross clamping the aorta; intracoronary perfusion of the recipient heart was not started during the operation. The patients were anticoagulated with heparin as part of the surgical procedure. The orifice of the right coronary artery was cannulated less than five minutes after removal of the heart from the patient and the artery was perfused with $2 \%$ buffered glutaraldehyde at a pressure of 130 $\mathrm{mm} \mathrm{Hg}$ at $4^{\circ} \mathrm{C}$ for 20 minutes. Because fresh tissue was needed for other studies a similar technique was not used on the left coronary artery. The right coronary artery, from its origin to the origin of the posterior descending coronary artery, was dissected free from the underlying heart and stored in buffered glutaraldehyde. The coronary artery was then divided into segments that were $1-1.5 \mathrm{~cm}$ long. Small portions of vessel wall $(0.2 \mathrm{~cm}$ long) were removed from the ends of each segment and processed for routine microscopy. The remaining part of each segment was processed routinely for scanning electron microscopy and critically point dried before being carefully bisected longitudinally and coated. with gold-palladium. The coated samples were examined in an ISI DS130 scanning electron micros cope, operating at a voltage of between 10 and $20 \mathrm{kV}$

\section{Results}

Where examination of the intima at low magnifica tions showed no atherosclerotic lesions the endo thelial surface was intact and the cells were aligned with their long axes in the direction of blood flow (fig) 1). Endothelial cells over atherosclerotic lesions of atP types, however, were irregularly arranged and varie? in size and shape (fig 2). Simple fatty streaks had ais intact endothelial covering (fig 3).

In all cases leucocytes adhered to the plasmof membrane of the endothelial cells in many areaso both over diffuse intimal thickening and localise plaques (fig 4). The surface of the underlying endo=thelial cell beneath adherent cells was often indente

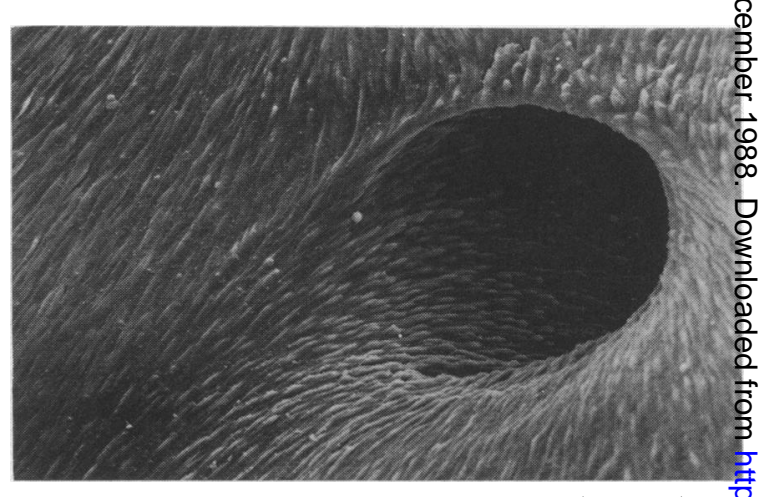

Fig 1 Normal intact endothelium at a point of arterial branching. The long axes of the cells are aligned in the direction of flow (original magnification, $\times 278$ ).

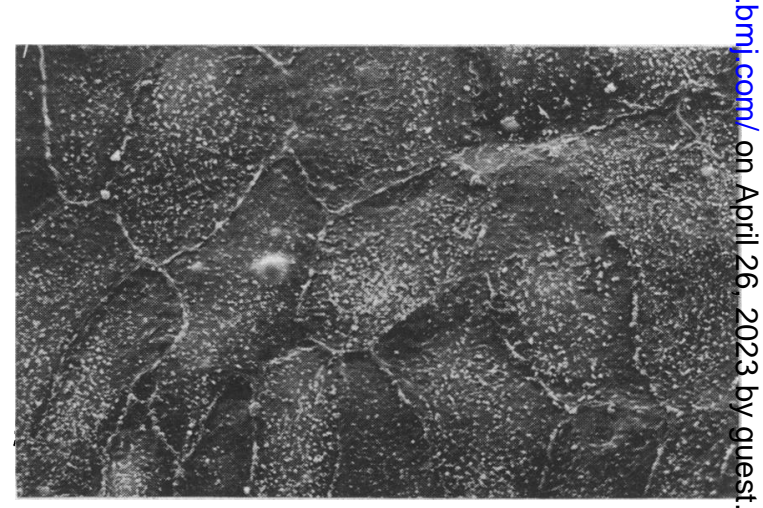

Fig 2 Intact endothelium over plaque surface showing variation in shape and size of cells and loss of normal orientation. The plasma membranes of the cells have short stubby surface processes (original magnification, $\times 1480$ ). 


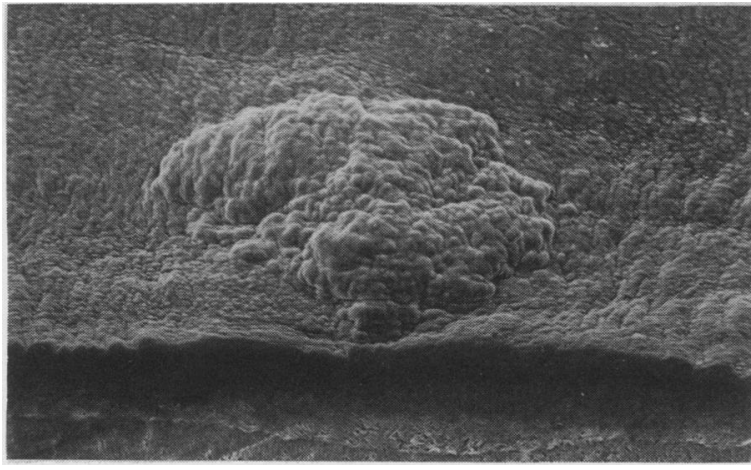

Fig 3 Micrograph showing a small and complete fatty streak. There is no defect in endothelial integrity but the cells are strikingly raised above the surface of the normal surrounding endothelium because of the subendothelial accumulation of foam cells (original magnification, $\times 106$ ).

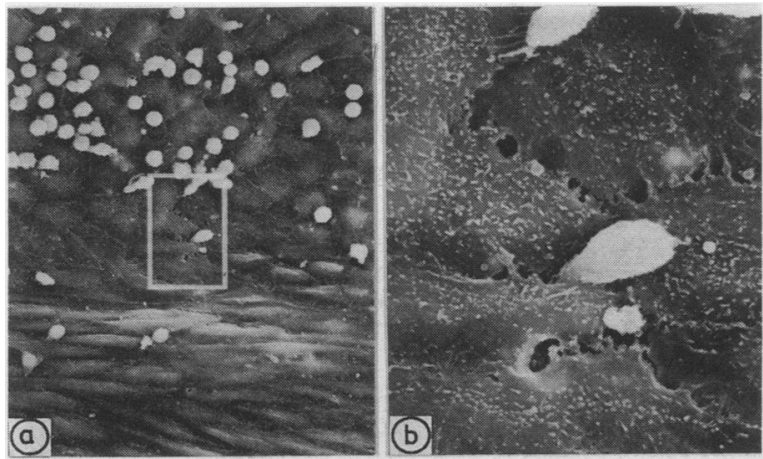

Fig 4(a)/(b) Leucocytes adherent to an intact endothelial surface over an atherosclerotic plaque. An adjacent area with endothelial cells showing more normal alignment is not associated with leucocyte adhesion (original magnification, $\times 407$ ). The higher magnification shows a leucocyte, probably monocytic, in transit between the endothelial cells (original magnification, $\times 2035$ ).

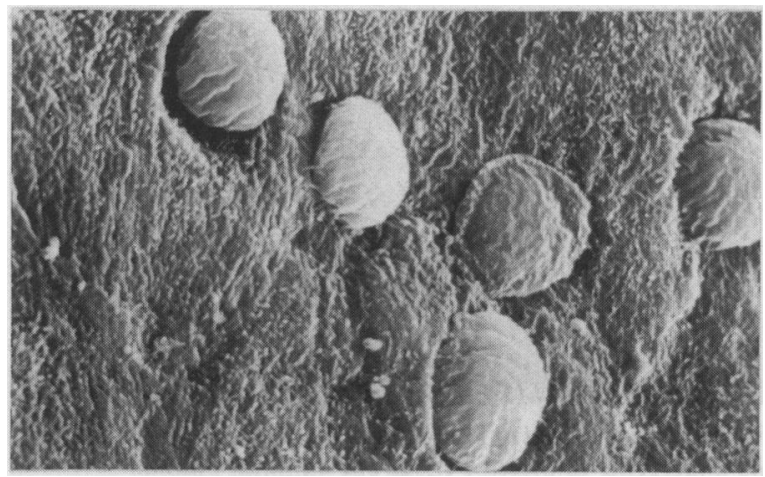

Fig 5 Leucocyte adherence to intact endothelial cells. The adherent cells appear to settle within small indentation in the plasma mambrane (original magnification, $\times 2200$ ).

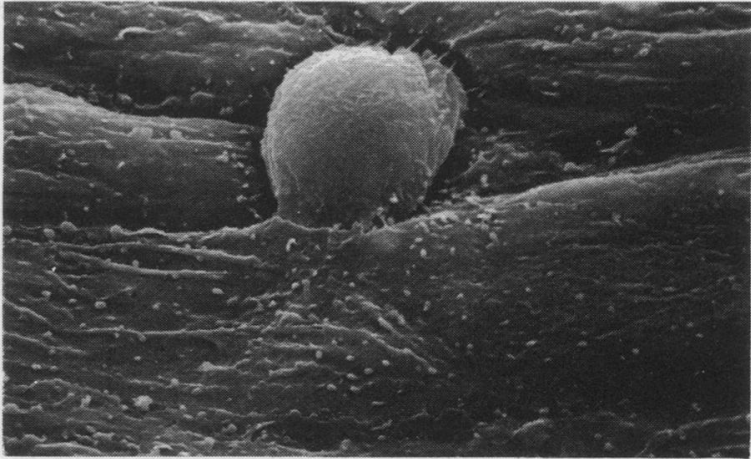

Fig 6 Leucocyte, part of which is inserted under the edge of an intact endothelial cell (original magnification, $\times 3870$ ).

(fig 5). Leucocytes seemed to be in transit through the endothelium (fig 6); some were strikingly elongated at one pole and attached to the subendothelium via a small but distinct gap in the endothelium (fig 7a and b). Many of the migrating leucocytes had a ruffled plasma membrane suggesting a monocytic origin. Where gaps in the endothelium were larger cells with similar morphological appearances could be seen in the most superficial portions of the intima just beneath the endothelial surface (figs 8 and 9).

In all six hearts there were defects in the endothelial surface over plaques; and the more severe the extent of intimal disease in any individual patient the more severe and extensive was this change. But endothelial damage was not, however, directly related to the presence or absence of stenosis; it was often found in segments of artery in which there was no significant obstruction. Exposure of subendothelial collagenous tissue took various forms. In some areas loss of a single endothelial cell caused a clearly demarcated defect in the surface; such defects were associated with the presence of adherent platelets (fig 10). Larger gaps in the endothelial surface were seen where groups of endothelial cells had been lost (fig 11). Endothelial denudation was often but not always associated with the presence of platelets (fig 12).

\section{Discussion}

All of the patients in this study were undergoing cardiac transplantation because they had advanced atherosclerosis. Morphological damage to the endothelium was common and widespread. Such a study cannot give information on the possible role of endothelial dysfunction in the early stages of atheroma, but it showed that in common with many animal models endothelial denudation in man is a late phenomenon. In this context "late" refers to the 

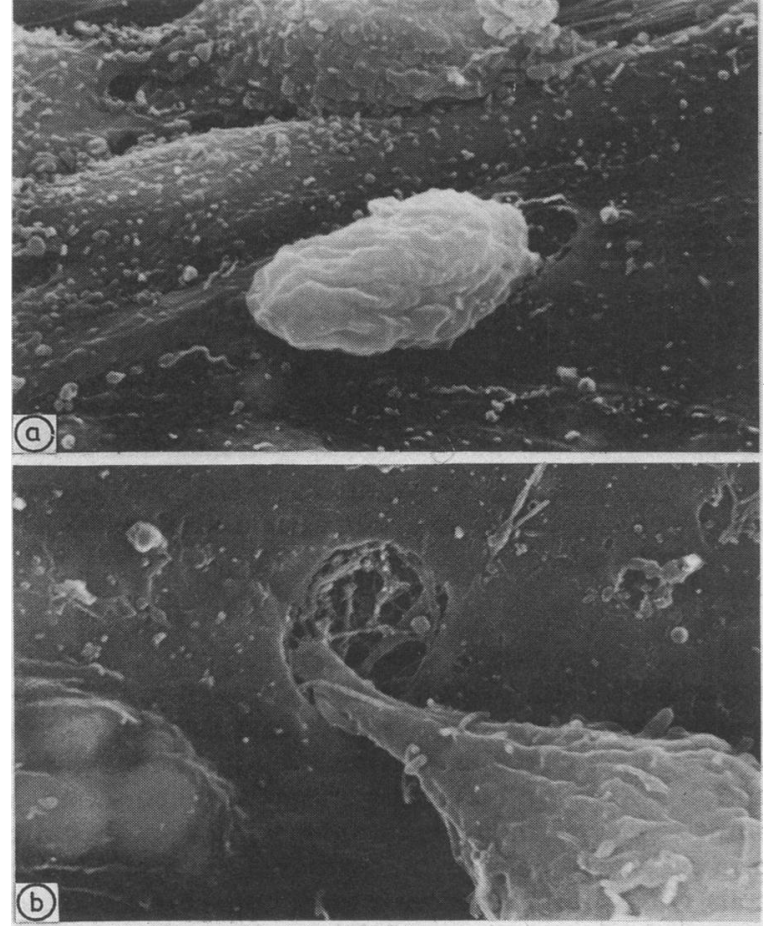

Fig 7 Leucocyte migration. In (a) the cell is closely applied to a small defect in the endothelial surface (original magnification, $\times 4430$ ). In (b) the cell is attached to a defect in the endothelium by a strand of cytoplasm. An adjacent area of intact endothelium shows a lipid containing cell immediately beneath the surface (original magnification, $\times 9800$ ).

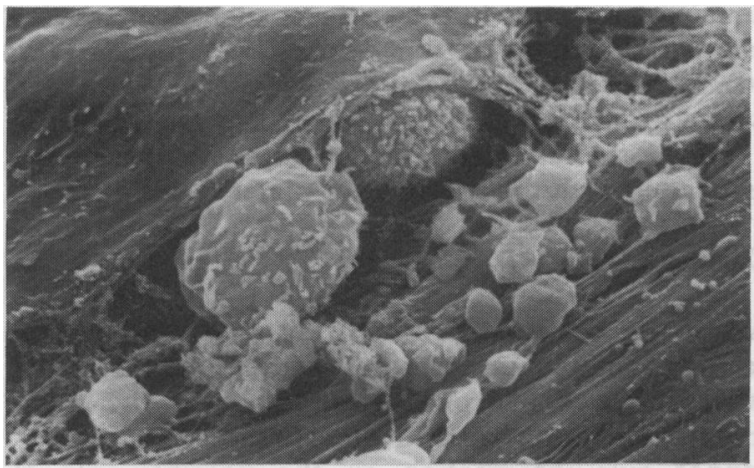

Fig 8 Fenestrations in the endothelial surface covering two macrophages which are immediately beneath the surface. There are platelets adhering to the exposed subendothelial tissue (original magnification, $\times 5300$ ).

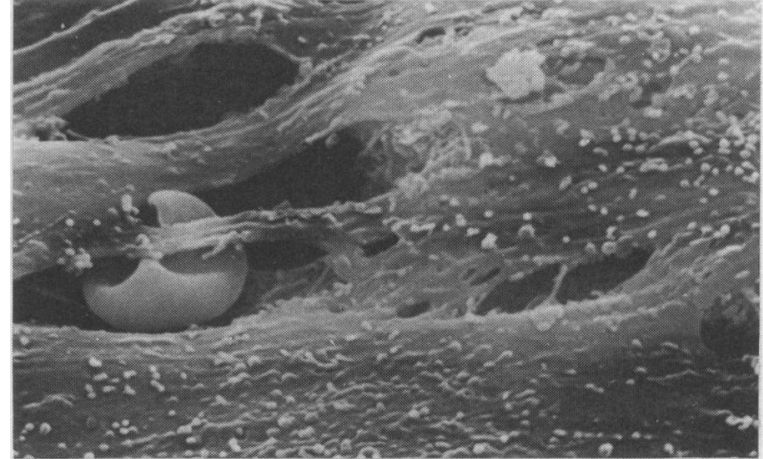

Fig 9 Endothelium in which there is a defect in the surface that exposes the underlying connective tissue, but no platelet adherence has occurred. A red cell is trapped under a strand of endothelial cytoplasm (original magnification, $\times 2690$ ).

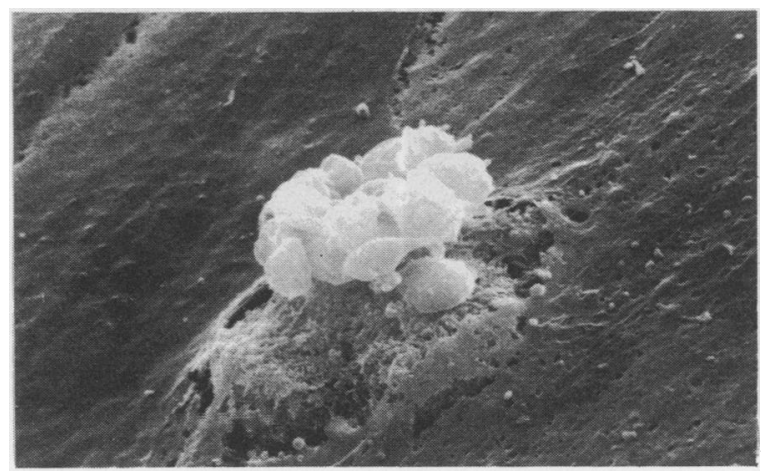

Fig 10 Loss of a single endothelial cell. The exposed surface is covered by platelets some of which have changed shape (original magnification, $\times 3570$ ).

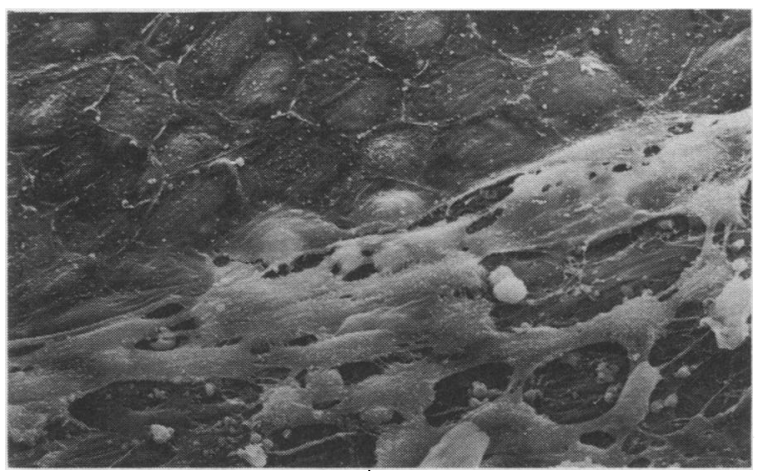

Fig 11 Large area of endothelial damage with exposure of the underlying connective tissue but minimal platelet adherence. An immediately adjacent area of endothelium is intact but of irregular pattern (original magnification, $\times 880$ ). 


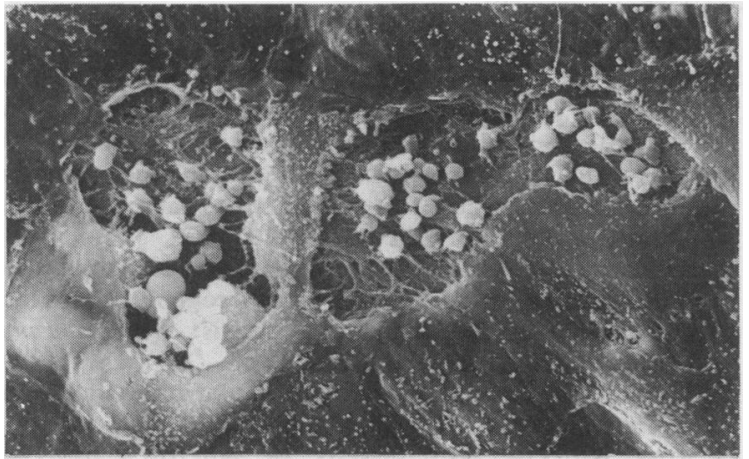

Fig 12 Endothelial damage and denudation with platelets adhering to the exposed subendothelial tissue (original magnification, $\times 1340$ ).

overall degree of intimal involvement and not the degree of stenosis caused by a particular plaque. Endothelial damage was present in many segments without significant obstruction, which shows that angiography is an insensitive method for the detection of diffuse non-stenosing intimal disease.

All the morphological changes noted in this study of human atherosclerosis have been seen in the lesions that develop as a consequence of hyperlipidaemia, whether diet related or inherited, in animal models. Our study showed that monocyte/ endothelium/platelet reactions were also present in human atherosclerotic lesions and gave clear evidence of both monocytic adhesion to an intact endothelial surface and focal endothelial denudation over more advanced plaques in the coronary arteries of patients who were not grossly hyperlipidaemic. We do not believe that the endothelial defects can be the result of artefact because many of them were covered by a layer of platelets, most of which had changed shape. Such a process is unlikely to have occurred during the preparation of the tissue samples. If the endothelial changes were purely secondary to the stress of awaiting cardiac surgery, with the inevitable increase in endogenous catecholamine release, we would not have expected to see a selective effect on the atheromatous lesion. All of the patients had morphologically intact endothelium in other areas.

A morphological study cannot establish the direction of migration of individual monocytes. Over early lesions, however, we saw portions of monocyte cytoplasm within the junctions between intact endothelial cells, which suggests that the monocytes were entering the intima. In more advanced atheromatous lesions macrophages were associated with larger defects in the endothelial surface. In these areas endothelial cells were stretched over underlying cells that bulged toward the lumen. Such major defects in the endothelium may well allow lipid filled monocytes to be released into the lumen. All the morphological changes seen in animals and taken to indicate emigration of lipid filled cells from the intima ${ }^{18}$ were also seen in our study of human material. The association of denuding endothelial damage with macrophages lying immediately beneath the surface also accords with a direct cytotoxic effect on the endothelium. Morphological studies cannot, however, elucidate the mechanism of such an effect; one of many possibilities is the generation of reactive oxygen species. ${ }^{19}$

The finding of endothelial denudation and platelet interaction with the vessel wall in animal models has given rise to the hypothesis that growth factors derived from platelets cause smooth muscle proliferation and plaque growth. ${ }^{21}$ The observed abnormal vasomotor responses of atheromatous arteries in both animal models and $\operatorname{man}^{22-24}$ have also been explained by endothelial damage and platelet deposition. ${ }^{25} 26$ The present study of human endothelium over atheromatous plaques indicates that these hypotheses are tenable in man.

The results reported here are preliminary. The degree of endothelial damage needs to be measured with regard to individual factors such as smoking and blood lipid levels as well as local factors such as the degree of stenosis and arterial geometry.

\section{References}

1 Gerrity RG, Naito HK, Richardson M, Schwartz CJ. Dietary induced atherogenesis in swine. Am J Pathol 1979;95:775-86.

2 Joris I, Zand T, Nunnari JJ, Krolikowski FJ, Manjo G. Studies on the pathogenesis of atherosclerosis. I. Adhesion and emigration of mononuclear cells in the aorta of hypercholesterolemic rats. Am J Pathol 1983; 113:341-58.

3 Gerrity RG. Role of the monocyte in atherogenesis. I. Transition of blood-born monocytes into foam cells in fatty lesions. Am J Pathol 1981;103:181-90.

4 Faggiotto A, Ross R, Harker L. Studies of hypercholesterolemia in the non human primate. I. Changes that lead to fatty streak formation. Arteriosclerosis 1984;4:323-40.

5 Faggiotto A, Ross R. Studies of hypercholesterolemia in the non human primate. II. Fatty streak conversion to fibrous plaque. Arteriosclerosis 1984;4:341-56.

6 Schwartz CJ, Sprague EA, Kelly JL, Valente AJ, Suenram CA. Aortic intimal monocyte recruitment in the normo- and hypercholestrolemic baboon (Papio cyanocephalus). Virchows Arch [A] 1985;405: 175-91.

7 Buja LM, Kita T, Goldstein JL, Watanabe Y, Brown MS. Cellular pathology of progressive atherosclerosis in the WHHL rabbit. An animal model of familial hypercholesterolemia. Arteriosclerosis 1983;3:87-101. 
8 Seddon AM, Woolf N, Laville A, et al. Hereditary hyperlipidemia and atherosclerosis in the rabbit due to overproduction of lipoproteins. Preliminary report of arterial pathology. Arteriosclerosis 1987;7:113-24.

9 Mitchinson MJ, Ball RY. Macrophages and atherogenesis. Lancet 1987;ii:146-8.

10 Gown AM, Tsukada T, Ross R. Human atherosclerosis II. Immunocytochemical analysis of the cellular composition of human atherosclerotic lesions. $\mathrm{Am} \mathrm{J}$ Pathol 1986;25:191-207.

11 Walker LN, Reidy MA, Bowyer DE. Morphology and cell kinetics of fatty streak lesion formation in the hypercholesterolemic rabbit. Am J Pathol 1986;25: 450-9.

12 Gerrity RG, Goss JR. Chemotactic responses of monocyte macrophages. A possible mechanism for their migration into atherosclerotic lesions. In: Schettler FG, Gotto AM, Middlehoff G, Habenicht AJR, Jurutaka KR, eds. Atherosclerosis. VI. Proceedings of the 6th international symposium. Berlin: Springer-Verlag, 1983:457.

13 Reidy MA. Biology of disease. A reassessment of endothelial injury and arterial lesion formation. $L a b$ Invest 1985;53:513-20.

14 Mazzone T, Hensen M, Chait A. Human arterial wall cells secrete factors that are chemotactic for monocytes. Proc Natl Acad Sci USA 1983;80:5094-7.

15 Alderson LM, Endemann G, Lindsey S, Pronczuk A, Hoover RL, Hayes KC. LDL enhances monocyte adhesion to endothelial cells in vitro. Am J Pathol 1986;123:334-42.

16 Rogers K, Hoover RL, Castellot JJ, Robinson JM, Karnovsky MJ. Dietary cholesterol induced changes in macrophage characteristics. Am J Pathol 1986, 125:284-91.

17 Valente AJ, Sprague EA, Nassiri MR, et al. Influence of plasma proteins on blood monocyte adherence to vascular endothelium. Arteriosclerosis 1984;4:450-60음

18 Gerrity RG. The role of the monocyte in atherogenesis $\bar{\omega}$ II. Migration of foam cells from atherosclerotie lesions. Am J Pathol 1981;103:191-200.

19 Schwartz CJ, Valente AJ, Sprague EA, et al. Monocyte macrophage participation in atherogenesis: inflam $\overrightarrow{0}$ matory components of pathogenesis. Semin Thromb Hemost 1986;12:79-86.

20 McMillan GC. Nature and definition of atherosclerosis Ann NY Acad Sci 1985;454:1-4.

21 Ross $R$. The pathogenesis of atherosclerosis-ang update. N Engl J Med 1986;314:488-500.

22 Ludmer PL, Selwyn AP, Shook TL, et al. Paradoxical vasoconstriction induced by acetylcholine in athero sclerotic coronary arteries. $N$ Engl J Med 1986, 315:1046-51.

23 Nabel EG, Ganz P, Gordon JB, Alexander RW, SelwynAP. Dilation of normal and constriction of athero-D sclerotic coronary arteries caused by the cold pressord test. Circulation 1988;77:43-52.

24 Harrison DG, Freiman PG, Armstrong ML, MarcusD ML, Heistad DD. Alterations of vascular reactivity in atherosclerosis. Circ Res 1987;61(suppl II):74-80.

25 Houston DS, Vanhoutte PM. Platelets, endotheliumpo and vasospasm. Circulation 1985;72:718-34.

26 Lam JYT, Chesebro JH, Steele PM, Badimon L Fuster V. Is vasospasm related to platelet deposition? Relationship in a porcine preparation of arteria injury in vivo. Circulation 1987;75:243-8. 